\title{
Assessing Student Responses to the Potential Conflict between Safety and Welfare in the American Society of Civil Engineers Code of Ethics
}

\section{Dr. Matthew Sleep P.E., Oregon Institute of Technology}

Matthew Sleep is an associate professor of civil engineering at Oregon Institute of Technology. Prior to Oregon Tech, Matthew received his PhD at Virginia Tech researching slope stability, levees, transient seepage and reliability. Matthew is from Nashville, TN and has worked for the United States Army Corps of Engineers and private consulting. He currently teaches and continues research on reliability and transient seepage.

Dr. Yasha Rohwer, Oregon Tech 


\section{Assessing student responses to the potential conflict between safety and welfare in the American Society of Civil Engineers code of ethics}

The first canon of the American Society of Civil Engineers (ASCE) code of ethics states that

"Engineers shall hold paramount the safety, health and welfare of the public..." While it may seem that safety, health, and welfare are all complementary to one another, we argue that there are situations where trade-offs exist between these important obligations of civil engineers. Our focus in this paper is on the tension between safety and welfare. Safety can be quite costly and that high cost can affect the welfare of an engineer's client-especially if that client is poor. Given this trade-off, we surveyed engineering students on how they would apply the code of ethics when navigating two hypothetical cases involving helical piles (foundation systems), which nicely illustrate this tension. In one hypothetical situation the client is quite wealthy, in the other the client is poor. Half of the students were first asked to review the code of ethics' first canon. Comparing student responses will help us understand the extent to which students consider their code of ethics when approaching a new project, and how they navigate the tension between welfare and safety.

\section{Introduction}

The first canon of the American Society of Civil Engineers (ASCE) code of ethics states that "Engineers shall hold paramount the safety, health and welfare of the public..." While it may seem that safety, health, and welfare are all complementary to one another, we argue that there are situations where trade-offs exist between these important obligations of civil engineers. Our focus in this paper is on the tension between safety and welfare and the response of students in an undergraduate, civil engineering program to this tension. Two hypothetical cases involving helical piles (foundation systems) were presented to six groups of students. In one hypothetical situation - a pool installation — the client is quite wealthy. In the other - a modest home foundation repair - the client is poor. Three of the six groups of students were first asked to review the code of ethics' first canon. After reviewing the canon, students were directed to reflect on the conflict between safety and welfare and to keep this in mind during their designs. Groups of students from years 1, 2 and 3 of the undergraduate program were surveyed.

The responses of students that did not review the canon were compared with those that did. Student responses were in the form of a number of helical piles to use for each design. The problems were designed to be technically similar. The responses show that students, across all years in the program and independent of whether they reviewed the first canon, used a higher factor of safety for the less wealthy client (the home) compared to the wealthy client (the pool). Using more piles for the home than safety actually requires would have a negative impact on the client's welfare, as the design is costlier. Despite highlighting to some students the negative 
impact to client welfare, these students still used more piles for the home compared to the pool. No statistical difference between responses from the groups were observed, suggesting no effect of directing students to focus on the welfare of the client and the first ASCE canon in their designs. Students consistently used the safer and costlier design solution in spite of the negative impact to client welfare.

\section{Balance of Safety, Health, and Welfare}

Given that civil engineers work on projects that can have a profound impact on the general wellbeing of the public, it is no surprise that the first canon of the American Society of Civil Engineers (ASCE) code of ethics reads "Engineers shall hold paramount the safety, health and welfare of the public and shall strive to comply with the principles of sustainable development in the performance of their professional duties" [1] Of all the canons in the ASCE code of ethics, the first canon is clearly the most important. After all, the canon lists the moral obligation to hold the safety, health, and welfare of the public paramount.

The first canon is plausible because it rules out actions that are clearly immoral—like cutting corners in construction that would put personal profit over the health, safety, and welfare of the public. Another virtue of the first canon is that it has a built-in procedure for helping solve potential moral conflicts that could arise. Since the safely, health, and welfare of the public are to be held paramount, engineers have guidance as to what considerations should win out in the case of potential moral conflict. For example, the fourth canon expresses the obligation of engineers to act as faithful agents to their clients, but this obligation can be overridden-if, for example, the client's requests would endanger the safety of the public. Hence, the first canon of the code of ethics lays out the strongest moral obligation of civil engineers. This clarity was not always present in past iterations of engineering codes. In fact, the word "paramount" was explicitly added to engineering codes to resolve potential conflicts between the different canons [10].

While professional codes of ethics, like the ASCE code, are valuable tools for engineers, they do have certain limitations. The codes are concise and presented in very general terms, and thus they include a certain amount of vagueness in how obligations are stated. General codes cannot specifically address all possible ethical issues that arise [7], [10]. Thus, professional codes must be interpreted [2]. In interpreting codes, we need to not only grasp the concepts used in the code, but also understand how they relate to one another.

For the purposes of this paper we are going to focus in on the first canon and show how there is a potential tradeoff between safety and welfare such that both cannot simultaneously be held paramount. This conflict can lead to issues when the code is applied to particular projects. It is unclear that the tradeoffs identified in this paper are being properly recognized and taught to engineering students. 
In the first canon, engineers are told to hold three things paramount: safety, health, and welfare. The first two items on the list seem to go together very well. After all, if safety is ignored, then health is endangered. One might get the impression the relationship between safety and welfare works the same way. Perhaps holding safety paramount is all that is required to also hold health and welfare paramount? Looking at how the first canon is abbreviated, on the ASCE website-as "Hold Safety Paramount"-certainly gives this impression; however, this is not the case. There is a potential tension between safety and welfare. That is, there are ways in which holding the safety of the client paramount may adversely affect that client's welfare.

To understand the tradeoff between safety and welfare, let us begin by looking at the complex concept of "welfare." Welfare in ethics is used in different ways [5]. Sometimes it is meant to refer to the material conditions that are important for an individual's life to go well-for example someone who was starving, lacked physical shelter, or had no access to healthcare would have poor welfare. Other times welfare is thought of more in mental terms. Are an individual's wishes or preferences being satisfied? Do they feel their life is going well? However, the word is defined and used in different fields, it is generally thought of as what is good for the individual or how a person's life is faring as a whole. For the purposes of this paper, these more general notions of welfare will suffice, and our analysis will be consistent with both the material and mental views of welfare.

Holding paramount the safety and welfare of the public, includes ensuring that a given project doesn't compromise the safety and welfare of the client. Unfortunately, safety often comes at a high cost, and that high cost can, in certain contexts, jeopardize the welfare of clients. If we understand welfare as what is good for the individual or how one's life is faring as a whole, it is easy to see how being impoverished can lead to compromised welfare. Lacking funds can lead to an inability to satisfy the basic material conditions necessary to lead a good life. Examples of this abound in the social science literature. For example, Jo C. Phelan et al. [9] state that low socioeconomic status is a cause of worse health and shorter lives. Furthermore, lacking funds can certainly impede an individual's ability to satisfy their preferences or wishes. Of course, more money doesn’t always make one's life better. At a certain point, accruing more money doesn't positively affect an individual's welfare [6]. But, for those at the lower end of the economic spectrum, it is hard to think that extremely high project costs would not affect their welfare. As Kahneman and Deaton note "low income is associated both with low life evaluation and low emotional well-being” [6, pp.16489].

This issue is further aggravated by the fact that engineers must use their judgment concerning what needs to be done to ensure safety [3]. Different views about what must be done to ensure safety can result in drastically different price tags for the client and hence, drastically different effects on the client's welfare. An exclusive focus on safety could lead to what is sometimes 
known as "Roman engineering," which—while guaranteeing safety—can compromise the welfare of the client by diverting funds they need for other things.

Holding safety paramount doesn't necessarily entail that welfare is also being held paramount. According to the ASCE code of ethics, both must be held paramount, which seems impossible in cases where the financial status of the client means that they are in conflict with one another. It is still possible to hold safety, health, and welfare above other duties, but it must be recognized that there will be tradeoffs within the first canon.

To properly interpret the first canon of the ASCE code of ethics and be able to use it in practice engineers must recognize the tradeoffs between safety and welfare. Knowledge of the ethical code and the ability to interpret it and understand the limitations of it should come at the earliest stages of education for engineers; however, it is unclear that students are obtaining this kind of understanding. This is why we conducted the survey of civil engineering students below.

\section{A Geotechnical Design Method}

The balance of safety, health and welfare is further complicated when considering the methods that engineers must rely on to design systems such as helical piles. Helical pilesare generally steel foundation systems with a central shaft and helical shaped bearing plates [12]. As shown in Figure 1 Error! Reference source not found., helical piles are used to resist downward forces from the reaction between the bearing plates and the soil in which they are driven.

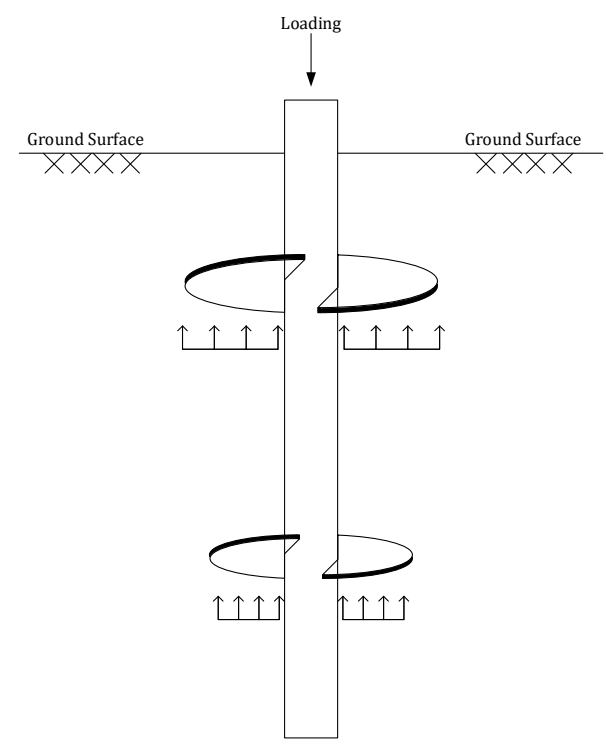

Figure 1 - Example of downward loading and soil reaction against a typical helical pile 
Helical piles have square or round axial shafts ranging from 1.5 inches to 6 inches in diameter. The loading plates, as shown in Figure 1, range from 8 to 16 inches in diameter [8]. The design of helical piles, to an extent practical, was formalized by the International Building Code (IBC) in 2007. The design for axial loading of a helical pile can be calculated from the following:

$$
P_{a}=0.5 P_{u}
$$

In Eq. 1, $\mathrm{P}_{\mathrm{a}}$ is the allowable load and $\mathrm{P}_{\mathrm{u}}$ is the least value of the structural capacity of the steel shaft or the bearing plate areas multiplied by the ultimate bearing capacity of the soil or the capacity determined from well-documented correlations with installation torque. The steel capacity is assumed to be a known quantity based on the steel manufacturer. The capacity of the soil, however, is a highly variable quantity. As stated in the IBC, the capacity can be determined by multiplying the area of the plates by the bearing capacity of the soil or measured installations torque from well-documented correlations. Both of these methods require the designing engineer to use his or her judgement on the soil's capacity.

Soil and rock, unlike common structural materials such as concrete and steel, have highly variable properties. As reported by Duncan [4], undrained strength of soil, which directly effects the axial capacity of a helical pile, can have a coefficient of variation between $13 \%$ and $40 \%$. This unknown strength is a function of both aleatoric variability and epistemic uncertainty. Epistemic uncertainty is the uncertainty generated by the unknown. In the case of soil strength, the unknown is due to limited subsurface investigation and soil testing. Epistemic uncertainty can be reduced by testing, but this is usually limited due to budget and time. Aleatoric variability is the natural randomness that exists in the physical world. Because soil and rock are natural materials, they have aleatoric variability due to the randomness of their placement, deposition and location. Aleatoric variability cannot be reduced with more soil testing as it is the natural variability inherent in the material. Unfortunately for engineers designing with helical piles, the soil they are relying on to resist loading will have a combination of both aleatory variability and epistemic uncertainty. This uncertainty further complicates the balance of safety and welfare in design applications.

Let us consider the first of two soil capacity methods for design of helical piles as described in the IBC, where $\mathrm{P}_{\mathrm{u}}$ is the sum of the areas of the helical bearing plates times the ultimate bearing capacity of the soil or rock comprising the bearing stratum. The ultimate bearing capacity of the soil $\left(Q_{u}\right)$, simplified here for a typical clay soil, can be found from $\mathrm{Q}_{\mathrm{u}}=\mathrm{cNc}$ where $\mathrm{c}=$ cohesion or strength of the soil and Nc is the bearing capacity factor (a constant). The cohesion, c, is the strength of the clay soil typically expressed in units of pounds per square foot (PSF). Even if this value were measured by a laboratory test for the clay soil the helical pile is being driven into, there would still exist the aleatory variability of the natural material. However, in many cases, the strength of the soil is estimated from some other soil property that is easily, and cheaply, measured such as soil type. Thus the engineer must use 'engineering judgement' to estimate how 
much axial capacity a helical pile can safely hold. A commonly used correlation for soil strength, cohesion, and consistency is shown in Table 1 from Terzaghi and Peck [11].

Table 1. Soil consistency and ranges of soil strength [11]

\begin{tabular}{|c|c|}
\hline Soil Consistency & Cohesion (psf) \\
\hline Very Soft & $<250$ \\
\hline Soft & $250-500$ \\
\hline Medium & $500-1000$ \\
\hline Stiff & $1000-2000$ \\
\hline Very Stiff & $2000-4000$ \\
\hline Hard & $>4000$ \\
\hline
\end{tabular}

Assume that the soil has a bearing capacity factor $\mathrm{Nc}=9$ and the bearing plates have an area of $5.5 \mathrm{ft}^{2}$. If the soil is described as very soft, the capacity of a single helical pile would be $5.5 \mathrm{ft}^{2} *$ 250 psf * $9 * 0.5=6187.5$ pounds. However, if the clay was simply described as soft, the capacity could be calculated at over 12,000 pounds. When balancing safety and welfare, it is safer for the engineer to assume a softer, weaker material, add additional piles at significant cost, and adversely affect the welfare of the client.

\section{Student Groups Surveyed}

Students enrolled in the Civil Engineering program at Oregon Institute of Technology were asked to complete two simple designs. One design was for a client that is very wealthy, and the other is for a client that is poor. A total of six separate groups of students were surveyed, with a total of 83 individual responses. The six groups were each a laboratory section of an individual course. Three courses were surveyed, each with two laboratory sections, for a total of six groups of students. The courses were Introduction to Engineering (ENGR $101-1^{\text {st }}$ year), Civil Engineering Materials (CE $212-2^{\text {nd }}$ year) and Introduction to Geotechnical Engineering (CE $311-3^{\text {rd }}$ year). For one laboratory section of each course, students were asked to solve two engineering problems with no discussion of the first canon of the ASCE code of ethics. For the second laboratory section of each course, students were first given a lecture and discussion period on the first canon of the ASCE code of ethics. This discussion included a reading of the canon, and then discussion on the potential conflict or trade-offs between safety, health and welfare. The discussion focused on whether the economic welfare of a client is important to an engineer's design. Students were instructed, explicitly, to keep in mind client welfare when they completed their designs. It was stated to this group of students that a higher factor of safety would result in more cost to the client resulting in reduced economic welfare. 
Table 2 illustrates the groups of students surveyed. Using these student groups allows for comparison between years in the program and the influence of a discussion of the ASCE canon.

Table 2. Student groups surveyed for this research

\begin{tabular}{|c|c|c|}
\hline Course Surveyed & $\begin{array}{c}\text { ASCE Canon Discussion Prior to } \\
\text { Survey }\end{array}$ & $\begin{array}{c}\text { Number of } \\
\text { Students }\end{array}$ \\
\hline ENGR 101 Lab 1 & NO & 13 \\
\hline ENGR 101 Lab 2 & YES & 13 \\
\hline CE 212 Lab 1 & NO & 16 \\
\hline CE 212 Lab 2 & YES & 17 \\
\hline CE 311 Lab 1 & NO & 17 \\
\hline CE 311 Lab 2 & YES & 7 \\
\hline
\end{tabular}

\section{Survey Conducted}

Two engineering problems were provided for the students to solve. One with an obviously wealthy client, and the other with a poor client. For each problem, students were given a force (in pounds) to resist with the installation of helical piles. The capacity of each pile was provided and it was stated that it will be field verified using the method described in the next section of this paper. The students were asked to first decide on an appropriate factor of safety for each design problem. The factor of safety was presented to the students as the capacity divided by the demand. The students were told that a factor of safety equal to one would mean that the capacity equals the demand. The students were instructed that any factor of safety chosen greater than one would mean that they were using more piles than the minimum. By starting with students choosing a factor of safety, the authors attempted to bypass any preconceived 'acceptable' factor of safety for these two problems. It was explained that a higher factor of safety would be more piles and have an increased cost to the client. The cases presented to the students are shown below.

\section{Case 1 - wealthy client}

An in-ground pool is being installed in a residential backyard. The residence is a 5 bedroom, 4bathroom home that is approximately 3800 square feet in size. The homeowner wishes to install an in-ground pool, complete with natural rock waterfall and waterslide. For this problem the helical piles were necessary to resist uplift from a potentially high groundwater table. The students were provided with the uplift force and capacity of each helical pile. Prior to giving the students this problem, a Google Image search was conducted to show them an image of the home and the proposed pool; these images are shown in Figure 2a-1b. 


\section{Case 2 - poor client}

A small, residential home is experiencing foundation failure. Cracking of walls, misaligned doors and windows and damaged utilities indicate the foundation is settling. Without remediation, the local municipality will condemn the building - making it unsuitable for occupancy. Using the same criteria in terms of size and capacity as the pool piles, how many piles should be installed to fully support this residential home? The Google Image search shown to the students for this scenario is shown in Figure 2c-1d.

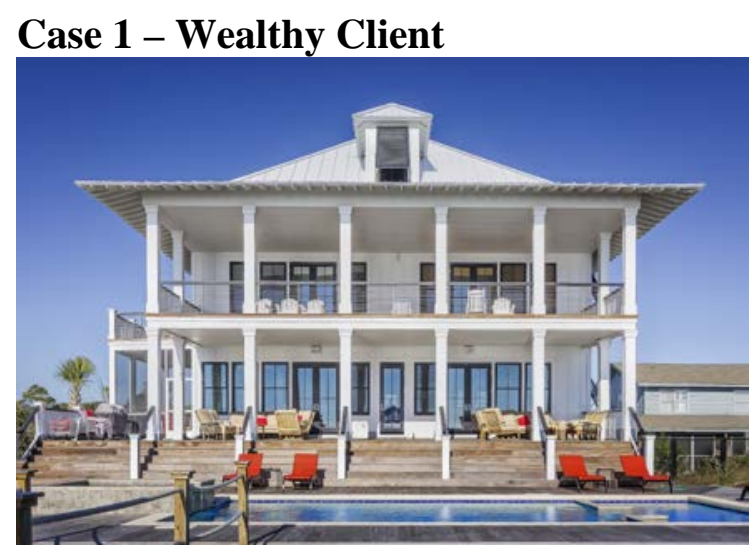

a

\section{Case 2 - Less Wealthy Client}

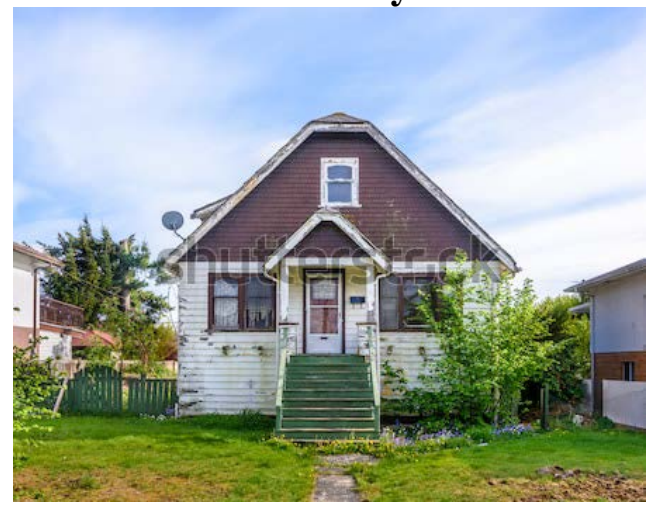

C

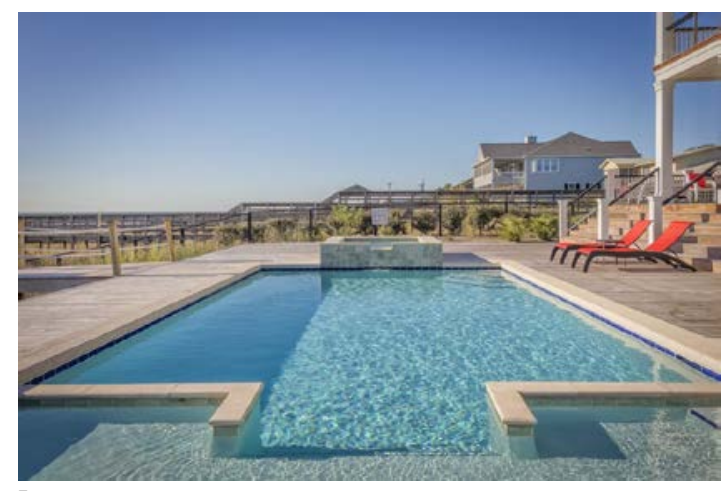

b

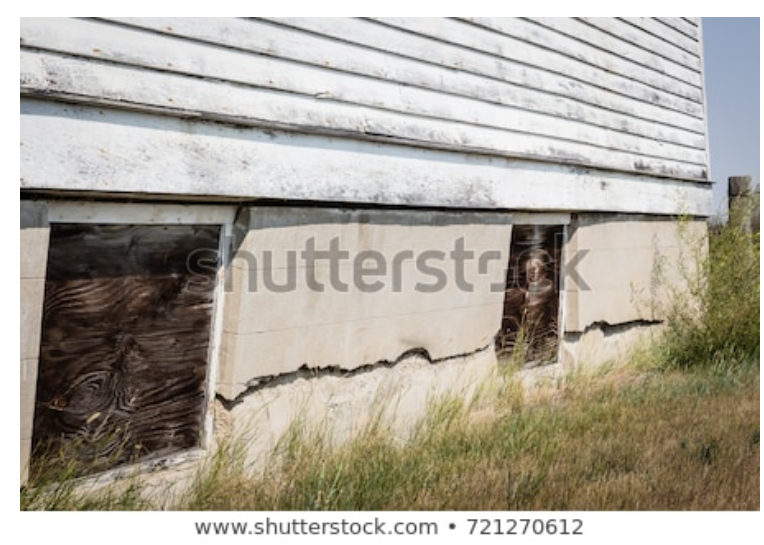

d

Figure 2 - Images shown to students prior to solving Case 1 and Case 2 (shown in class from Google Image Search - Prexel and shutterstock open source images)

\section{Survey Results}

The results of the student's designs are shown in Figure 3. Because different amounts of loading were used for Case 1 and Case 2, to prevent a biased response, the results are shown as factor of safety which is defined simply as the capacity divided by the demand. When the factor of safety is greater than 1 , students used more piles than necessary. 


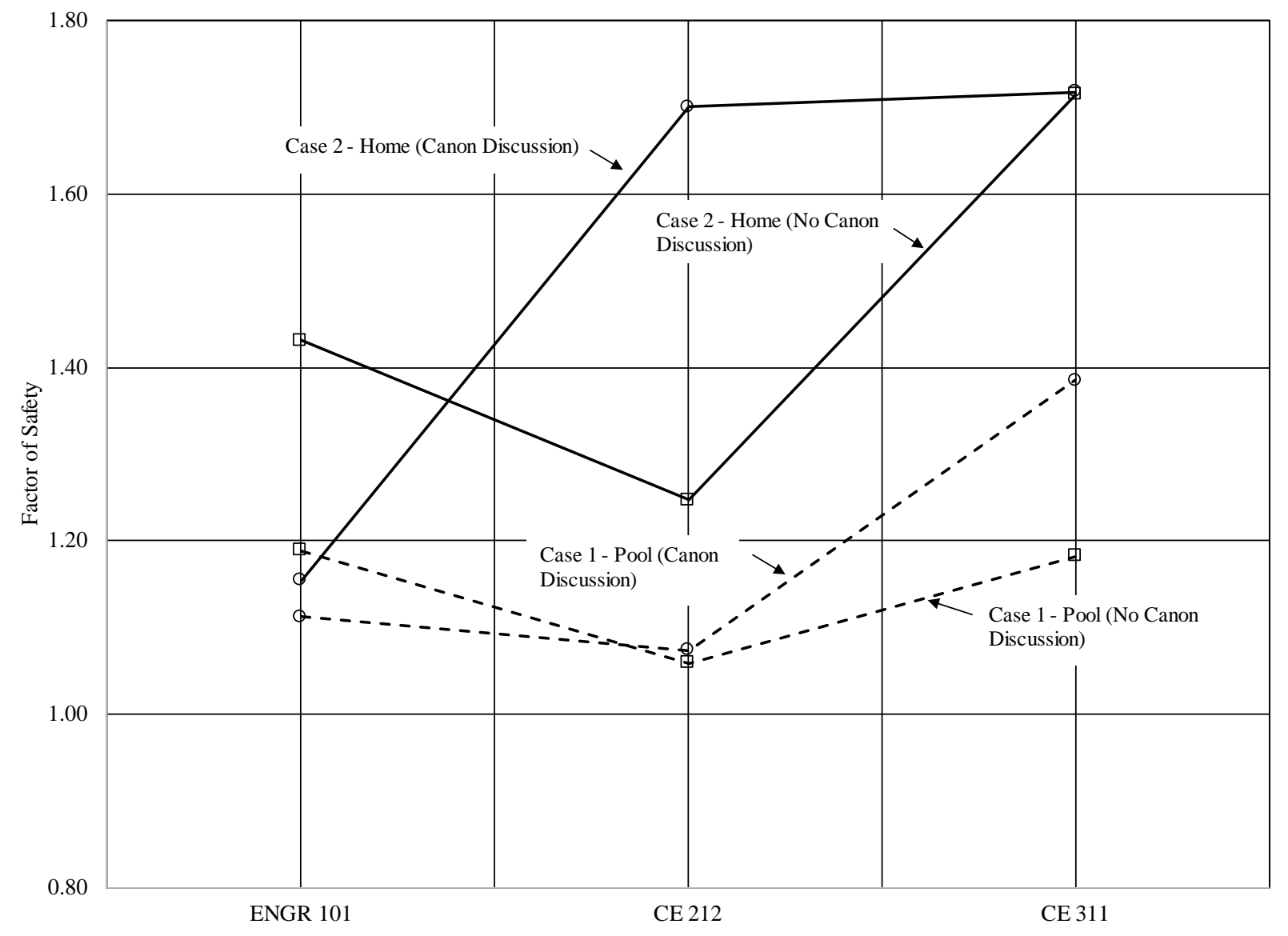

Figure 3 - Results of the student design for Case 1 (Pool) and Case 2 (Home) with and without a discussion on the ASCE Code of Ethics canon 1

Visual assessment of the data indicates that a discussion of the ASCE Code of Ethics, with particular attention to canon 1 and the balance of safety and welfare, influenced the student's designs insignificantly. There does, however, appear to be a significant difference between Case 1 and Case 2 in terms of factor of safety. To investigate this further, statistical analyses of the data were performed in the form of a two sample t-test at the $95 \%$ confidence level. The results of these tests are shown in Table 3. These results indicate that a focused discussion on the ASCE Code of Ethics canon 1, with respect to welfare and safety, had little effect on students' designs independent of time in the civil engineering program. There do appear to be statistically significant differences, independent of time in the civil engineering program and with or without a discussion of the ASCE Code of Ethics Canon 1, between Case 1 and Case 2 designs. 
Table 3. Results of two sample t-tests on the means

\begin{tabular}{|c|c|c|}
\hline \multicolumn{2}{|c|}{ Two Sample t-tests (95\% Confidence Level) } \\
\hline \multicolumn{2}{|c|}{$\begin{array}{c}\text { Tomparing in each case no discussion of the ASCE Canon vs. a discussion of the ASCE } \\
\text { Canon }\end{array}$} \\
\hline Test & $\begin{array}{c}\text { Tailed P- } \\
\text { Value }\end{array}$ & $\begin{array}{c}\text { Significant Difference in the Mean } \\
\text { Values? }\end{array}$ \\
\hline ENGR 101 Case 1 (Pool) & 0.5027 & NO \\
\hline ENGR 101 Case 2 (Home) & 0.19207 & NO \\
\hline CE 212 Case 1 (Pool) & 0.612 & NO \\
\hline CE 212 Case 2 (Home) & 0.1125 & NO \\
\hline CE 311 Case 1 (Pool) & 0.2499 & NO \\
\hline CE 311 Case 2 (Home) & 0.9895 & \begin{tabular}{c} 
Non \\
\hline
\end{tabular}
\end{tabular}

\begin{tabular}{|c|c|c|}
\hline \multicolumn{3}{|c|}{ Two Sample t-tests (95\% Confidence Level) } \\
\hline \multicolumn{2}{|c|}{ Comparing all of Case 1 to Case 2 with a Discussion of the ASCE Canon } \\
\hline Test & $\begin{array}{c}\text { Two Tailed P- } \\
\text { Value }\end{array}$ & $\begin{array}{c}\text { Significant Difference in the Mean } \\
\text { Values? }\end{array}$ \\
\hline 101,212 and 311 & 0.0268 & YES \\
\hline
\end{tabular}

\begin{tabular}{|c|c|c|}
\hline \multicolumn{3}{|c|}{ Two Sample t-tests (95\% Confidence Level) } \\
\hline \multicolumn{2}{|c|}{ Comparing all of Case 1 to Case 2 without a Discussion of the ASCE Canon } \\
\hline Test & $\begin{array}{c}\text { Two Tailed P- } \\
\text { Value }\end{array}$ & $\begin{array}{c}\text { Significant Difference in the Mean } \\
\text { Values? }\end{array}$ \\
\hline 101,212 and 311 & 0.0043 & YES \\
\hline
\end{tabular}

For the students surveyed with the Code of Ethics discussion, an additional two questions were provided at the end of the survey (Figure 4). Correlation coefficients were calculated using the number of piles designed as the predicted variable, and the survey results (1-5) as the predictor variable. These results are presented in Table 4. As shown, for ENGR 101 students $\left(1^{\text {st }}\right.$ year) there is a slight negative correlation, indicating that the Code of Ethics canon 1 had little perceived effect on their designs. Positive correlations were observed for the CE 212 ( ${ }^{\text {nd }}$ year) and CE 311 ( $3^{\text {rd }}$ year) students. For the third year students, there is a significant difference between the correlation coefficient for Case 1 and Case 2, indicating that the students perceived a greater influence of the Code of Ethics canon 1 for the home as compared to the pool. 
Rank the following statements on a scale of 1 to 5 with 1 indicating that you strongly disagree with the statement and 5 indicating that you strongly agree with the statement.

1. The ASCE Code of Ethics First Canon influenced my design of the residential swimming pool.

\begin{tabular}{|c|c|c|c|c|c|}
1 & 2 & 3 & 4 & 5 \\
\hline Strongly Disagree & & \multicolumn{3}{r|}{ Strongly Agree }
\end{tabular}

2. The ASCE Code of Ethics First Canon influenced my design of the residential home.

\begin{tabular}{|l|l|l|l|l|}
1 & 2 & 3 & 4 & 5 \\
\hline Strongly Disagree & & & & Strongly Agree
\end{tabular}

\section{Figure 4 - Survey questions given to students after completing their designs}

Table 4. Correlation coefficients and averages for and between questions 1 and 2 from Figure 4

\begin{tabular}{|c|c|c|}
\hline \multicolumn{3}{|c|}{ ENGR 101} \\
\hline & Case 1 - Pool & Case 2 - Home \\
\hline Mean & 4.15 & 4.54 \\
\hline Median & 4.00 & 5.00 \\
\hline Correlation & -0.16 & -0.08 \\
\hline \multicolumn{3}{|c|}{ CE 212} \\
\hline & Case 1 - Pool & Case 2 - Home \\
\hline Mean & 3.24 & 3.41 \\
\hline Median & 3.00 & 3.00 \\
\hline Correlation & 0.22 & 0.19 \\
\hline \multicolumn{3}{|c|}{ CE 311} \\
\hline & Case 1 - Pool & Case 2 - Home \\
\hline Mean & 3.14 & 4.14 \\
\hline Median & 3.00 & 4.00 \\
\hline Correlation & 0.17 & 0.80 \\
\hline
\end{tabular}

\section{Conclusions}

Two hypothetical engineering problems were presented to students in the Civil Engineering program in their first, second and third years. For each of these three groups of students, two subgroups were identified. One subgroup was presented the engineering problems with no introductory information. The second subgroup was presented with the ASCE Code of Ethics first canon prior to the engineering problem. The first canon was discussed with the students, 
emphasizing the potential conflict between safety and welfare, particularly when the client is poor or wealthy.

Results from the students' engineering designs show that for all years of students, there is significant difference in their designs between a wealthy (Case 1) and poor (Case 2) client. For the wealthy client and their pool design, students chose a smaller factor of safety than for a less wealthy client and their home.

If we observe the results of the home design problem only, without a comparison to the pool, students appear to be unaffected by a discussion of the economic consequences to the client. Three of the six groups were presented the problem with no discussion of the economic impacts to the client or the first canon. The other three groups, one of each course, were specifically told that a higher factor of safety would mean a more expensive solution to the client and would result in negative impact on their welfare. When we compare these two subgroups, no statistical difference in chosen factor of safety is observed. These results suggest that the engineering judgement of the students, as indicated by their chosen factor of safety, is either not impacted by economic welfare of the client, or other considerations, such as safety, overcome any impact.

When students were asked if the ASCE first canon impacted their designs, very little correlation was observed between a high perceived impact and the number of piles used. The exception to this was for third year students. For these students, there was a high level of positive correlation (0.70) between their perceived impact of the ASCE first canon and the number of piles they chose for the home design.

It is hypothesized that an emphasis on safe engineering designs in the curriculum of the engineering program may impact student's engineering judgement to a greater extent than welfare. This is illustrated by using a higher factor of safety for the home compared to the pool.

\section{Limitations of Study}

This study compared a pool to a home to represent a wealthy and poor client respectively. These different types of designs may have impacted student responses. Students may have been less comfortable with balancing safety and welfare for a home as compared to a pool. The fact that students consistently used a higher factor of safety for the home could be because of what homes represent in our culture (shelter, family, security, etc.). Alternatively, it could reflect conscious or unconscious adjustment of risk assessment based on the likely frequency of occupancy. People generally spend much more time in their homes than in their pools. For both these reasons, it is understandable that students would be more risk averse when designing a home versus a pool. To help mitigate this potential complication, future surveys should use the same kind same project, two homes for example, for the cases in the survey. In addition, students were not given a budget for the projects. When told that helical piles were used, students were told that each would cost the client $\$ 6,000.00$. 


\section{Discussion and Future Work}

These results may also reflect lack of significant focus on ethics and the process of ethical reasoning in engineering education. Engineering students understandably focus on calculations and methods, since engineers are applied scientists. The principal content of engineering training comprises understanding and manipulating the physical world. Ethics focuses on what we ought to do, how we should treat one another, and what kind of person we ought to be. Scientists are primarily concerned with investigating what is and ethicist are primarily concerned with investigating what ought to be. However, both domains are important to one another. Ethicists need to get the facts straight to produce good ethical arguments, and scientists need to understand how their discoveries and practices can morally affect individuals. If a student's education typically follows the traditional "silo" model of higher education, then regrettably, they will often fail to recognize and appreciate the important the connections between the domains. A robust focus on ethics and the relations between the empirical and the normative could help.

One way to more thoroughly investigate this potential gap in education is to extend this kind of survey to practicing engineers who teach. If the practicing engineers fail to recognize the potential conflict between safety and welfare, it is not surprising their students would as well.

\section{References}

[1] American Society of Civil Engineers. Code of Ethics. https://www.asce.org/code-of-ethics/ 2017.

[2] Davis, M. “Professional responsibility: Just following the rules?”. Business \& Professional Ethics Journal, 18(1), pp. 65-87, 1999.

[3] Duncan, J.M. and Sleep, M.D. “The need for judgement in geotechnical reliability studies.” Georisk - Assessment and Management of Risk for Engineered Systems and Geohazards. 11(1) pp. 1-5, 2016.

[4] Duncan, J. "Factors of safety and reliability in geotechnical engineering”. Journal of Geotechnical and Geoenvironmental Engineering ASCE, 126(4): pp. 307-316, 2000.

[5] Hansson, Sven Ove and Grüne-Yanoff, Till, "Preferences", The Stanford Encyclopedia of Philosophy (Summer 2018 Edition), Edward N. Zalta (ed.), URL = $<$ https://plato.stanford.edu/archives/sum2018/entries/preferences/>.

[6] Kahneman, Daniel, and Angus Deaton. "High income improves evaluation of life but not emotional well-being." Proceedings of the national academy of sciences 107.38, pp. 1648916493, 2010.

[7] Martin, Mike W., and Roland Schinzinger, Ethics in Engineering. New York: McGraw Hill, 1996. 
[8] Perlow, M., "Helical Pile Acceptance Criteria, Design Guidelines, and Load Test Verification.” In Geo-Frontiers 2011. https://doi.org/10.1061/41165(397)11.

[9] Phelan, J. C., Link, B. G., \& Tehranifar, P. "Social conditions as fundamental causes of health inequalities: theory, evidence, and policy implications." Journal of health and social behavior, 51(1_suppl), S28-S40, 2010.

[10] Schinzinger, Roland, Mike W. Martin, Introduction to Engineering Ethics. New York: McGraw Hill, 2000.

[11] Terzaghi, K. and Peck, R.B., Soil Mechanics in Engineering Practice, John Wiley, New York, 1967.

[12] Willis, D., Ram Jack Technical Manual. Version 1.0. p. 120, 2015. 